\title{
A Combination of Fertility Signals and Aggression Regulates Reproduction in the Ant Gnamptogenys striatula
}

\author{
Els Lommelen • Tom Wenseleers • \\ Christine A. Johnson • Falko P. Drijfhout • \\ Johan Billen • Bruno Gobin
}

Revised: 21 December 2009 / Accepted: 19 March 2010 /

Published online: 10 April 2010

(C) Springer Science+Business Media, LLC 2010

\begin{abstract}
Approximately 150 ant species are facultatively or obligately queenless whereby mated workers assume the role of the queen. In many of these species a reproductive dominance hierarchy is established by way of aggressive interactions. Top-ranking workers, which are typically the most fecund, acquire a characteristic cuticular hydrocarbon profile. We studied the temporal dynamics of this chemical change and associated interplay with observed aggressive interactions in an experimentally orphaned colony of the facultatively queenless ant Gnamptogenys striatula. Our observations and chemical analyses demonstrate that chemical fertility signals played a major role in the establishment of a dominance hierarchy and aggression settled dominance relationships only when ants had identical hydrocarbon profiles. Moreover, individuals with a higher potential fertility, in this experiment reflected in a higher ovariole number, are shown to have a better chance of becoming a reproductive.
\end{abstract}

Keywords Reproductive conflict · fertility signalling · gas chromatography · solid phase micro-extraction · Gnamptogenys striatula $\cdot$ queenless ants

E. Lommelen $(\bowtie) \cdot T$. Wenseleers $\cdot$ J. Billen

Zoological Institute, K.U.Leuven, Naamsestraat 59, Box 2466, 3000 Leuven, Belgium

e-mail: els.lommelen@gmail.com

C. A. Johnson

The American Museum of Natural History, Division of Invertebrate Zoology,

Central Park West at 79th Street, New York, NY 10024, USA

F. P. Drijfhout

Chemical Ecology Group, Lennard-Jones Laboratories, Keele University, Staffordshire ST5 5BG, UK

B. Gobin

PCS Research Centre for Ornamental Plants, Schaessestraat 18, 9070 Destelbergen, Belgium 


\section{Introduction}

Ant colonies are often considered as models of cooperation (Hölldobler and Wilson 1990). Conflicts, however, can also arise among society members (reviewed in Bourke 2005; Bourke and Franks 1995; Ratnieks et al. 2006). In insect societies, the most severe conflicts occur in species where colony members are reproductively totipotent, that is, able to mate and produce both male and female offspring (Monnin and Ratnieks 2001; Ratnieks et al. 2006). Reproductive totipotency occurs in species where queen-worker dimorphism is either weak or absent, such as polistine and stenogastrine wasps and halictid and allodapine bees (Strassmann et al. 2002; Wilson 1971). In a number of poneromorph ant species, both queen and worker castes are also able to reproduce, and some of these species have secondarily lost the queen caste altogether. In the latter, colonies are headed by one or more mated workers or "gamergates" (Monnin and Ratnieks 2001; Peeters and Crewe 1984; Ward 1981).

Totipotency greatly increases the potential for conflict, as any individual in the colony has the ability to replace the existing breeder (Monnin and Ratnieks 2001; Monnin et al. 2002; Hart and Ratnieks 2005), to become an additional breeder (Liebig et al. 1999) or to leave the colony and found a nest independently (Reeve and Keller 2001). Furthermore, when colonies become orphaned, an intermittent period of conflict can break out over breeding rights, which often results in widespread dominance interactions (e.g. Cuvillier-Hot et al. 2002, 2004a, b; Gobin et al. 2001; Ito 1993a; Liebig et al. 1998; Monnin and Peeters 1999; Oliveira and Hölldobler 1991; Powell and Tschinkel 1999; Trunzer et al. 1999). The level and frequencies of these aggressive interactions varies among species. Some species show virtually no dominance interactions (Sledge et al. 2001; Tay and Crozier 2000; Ware et al. 1990; Wildman and Crewe 1988), whereas aggression in other species can last for up to 5 weeks at average frequencies of six interactions per worker per hour (Gobin et al. 2001). Ultimately, these interactions result in the establishment of a stable dominance hierarchy and the selection of one or more new breeders from among the top-ranking individuals, after which aggression diminishes (Cuvillier-Hot et al. 2002, 2004a, b; Gobin et al. 2001; Monnin and Peeters 1999).

Cuticular hydrocarbon profiles that are explicitly linked to fertility are common for many ant species (reviewed by Monnin 2006). Through such chemical cues, workers have access to information about each other's fertility (D'Ettorre et al. 2004), and adapt their behaviour accordingly. Individuals with low fertility, for instance, can concede reproduction to nestmates that bear a signal associated with greater fertility. In this way, individuals can avoid using costly if not fatal aggressive interactions (Cole 1986; Gobin et al. 2003; Molet et al. 2005; Monnin and Ratnieks 1999). Alternatively, they can use these cues to prevent (i.e. police) low-fertility workers from attempting to allocate energy to reproduction in the presence of highly fertile and, hence, more capable reproductives (Dietemann et al. 2005; Gobin et al. 1999; Hartmann et al. 2003, 2005; Iwanishi et al. 2003; Kawabata and Tsuji 2005; Kikuta and Tsuji 1999; Liebig et al. 1999). It is thought that chemical fertility signals are mainly used to help maintain a stable dominance hierarchy, and that aggression is used mostly in orphaned colonies to aid in the establishment of a new dominance hierarchy (Cuvillier-Hot et al. 2004b). Nevertheless, as yet, the exact 
interplay between the relative roles of aggression and chemical fertility signals in regulating reproduction in queenless ants remains to be determined.

Here we present a first study of the relationship between the emission of chemical fertility signals and aggression using an orphaned colony of the facultatively queenless ectatommine ant Gnamptogenys striatula Mayr (Blatrix and Jaisson 2000). In an earlier study, Lommelen et al. (2006) identified cuticular hydrocarbons that are linked to fertility in this species. In the present study, we use repeated chemical sampling via non-invasive solid phase micro-extraction (SPME) to study the detailed temporal changes in cuticular hydrocarbon profiles. We then link these results to observations of agonistic interactions to determine whether aggression or fertility signals take precedence in regulating reproduction in this species. This project is presented as a case study on one experimental worker group, since both the repeated chemical sampling of various individuals via SPME and the detailed behavioural observations were very labour-intensive. In addition, by focusing on just a single colony, we could better tease apart the detailed dynamics on the individual cuticular hydrocarbon profiles over time.

\section{Methods}

\section{Study Species}

Gnamptogenys striatula is a New World ectatommine ant species. Colonies can be headed by one or several queens, or by several mated workers or gamergates (Blatrix and Jaisson 2001). They generally reproduce by budding or colony fission (Giraud et al. 2000), after which reproductives in the colony engage in a limited degree of dominance interactions to regulate dominance (Blatrix and Jaisson 2000). In queenless colonies, fertile workers perform sexual calling behaviour inside or near the nest (Blatrix and Jaisson 2000; Giraud et al. 2000). Other workers bring males found nearby into the nest, where the males may mate with several workers that display sexual calling behaviour (Blatrix and Jaisson 2000). Each individual worker though generally mates only once (Giraud et al. 2000). Unmated workers can also develop oocytes in their ovaries, thus mating is not a precondition for ovarian activity (Blatrix and Jaisson 2000), and mating in itself does not influence the ants' cuticular hydrocarbon profiles (Lommelen et al. 2006).

For this experiment, we used a colony containing ca. 300 workers and several gamergates, which was collected in Santa Rosa National Park, Costa Rica, in October 2003, and then brought to the laboratory in Belgium, where it was housed in a Janet-type nest box with plaster of Paris flooring (Hölldobler and Wilson 1990).

\section{Experimental Set-Up}

At the start of the experiment, we chose six newly emerged workers with yellowish cuticles from a gamergate-right colony and marked them with thin copper wire tied to the petiole, as workers at this stage are too fragile to be paint-marked. One week later, each worker was given a unique marking with a paint spot on either the thorax or abdomen with colour paint markers (Mitsubishi Pencil Co.). Subsequently, the 
focal ants were sampled chemically using solid phase micro-extraction (SPME) (see below). Three days after initial chemical sampling, when the ants were about 2 weeks old, five of the six workers (Nos. 1 to 5) were used to create an orphaned group. For this, the five workers were placed together with ten foragers (i.e. workers that leave the nest cavity frequently) and three larvae in a separate nest box $(119 \times 59 \times 55 \mathrm{~mm})$ with a glass-covered cavity $(15 \times 15 \times 3 \mathrm{~mm})$. The remaining worker (No. 6) was kept with the mother colony to serve as a control. All marked ants, including worker No. 6 in the mother colony, and two foragers were chemically sampled using SPME (as described below) every 2 days for 15 days, and then every 2 or 3 days until the end of the experiment, totalling 12 days of chemical sampling. On the days in between, gamergates from the mother colony were sampled for comparison. To describe the changes in the chemical profiles of the ants, we focused on the changes in 9-, 11-, 13-methylhentriacontane and 3,11-, 3,13-, 3,15-, dimethylhentriacontane, which were shown in an earlier study to be characteristic of non-fertile and fertile workers, respectively (Lommelen et al. 2006). We quantified 14 additional hydrocarbons (Table 1) that are also correlated with fertility (Lommelen et al. 2006). The colony was videotaped for the entire duration of the experiment (23 days, $552 \mathrm{~h}$ ). The videos were then analyzed in detail, and aggressive interactions scored as described below. At the end of the experiment, workers were dissected to determine ovarian development.

Table 1 List of Compounds that were Quantified for This Study. The Relative Fertility Factor Represents the Concentration of Each Compound for Fertile Workers When Standardizing the Concentration of Infertile Workers as Being ' 1 ' (cf. Lommelen et al. 2006). Peak Numbers Correspond to Numbers on the Total Ion Chromatograms Shown in Fig. 1

\begin{tabular}{|c|c|c|}
\hline Peak & Compound name & Relative fertility factor \\
\hline 1 & 11- and 13-methylnoneicosane & 0.36 \\
\hline 2 & 3-methylnoneicosane & 4.90 \\
\hline 3 & 3,15-dimethylnoneicosane & 23.37 \\
\hline 4 & 1-hentriacontene & 0.49 \\
\hline 5 & 9-, 11- and 13-methylhentriacontane & 0.42 \\
\hline 6 & 3,11-, 3,13- and 3,15-dimethylhentriacontane & 11.65 \\
\hline 7 & 10,14- and 8,12-dimethyldotriacontane & 0.30 \\
\hline 8 & 4,10-, 4,12- and 4,14-dimethyldotriacontane & 3.42 \\
\hline 9 & 9-, 11- and 13-methyltritriacontane & 0.39 \\
\hline 10 & 9,21-, 9,23- and 11,23-dimethyltritriacontane & 0.38 \\
\hline 11 & 3,11-, 3,13- and 3,15-dimethyltritriacontane & 17.74 \\
\hline 12 & 4,x-dimethyltetratriacontane & 1.33 \\
\hline 13 & 3,13- and 3,15-dimethylpentatriacontane & 10.92 \\
\hline 14 & 3,11,15-trimethylpentatriacontane & 3.14 \\
\hline 15 & 3,13- and 3,15-dimethylheptatriacontane & 41.69 \\
\hline 16 & 3,11,15-trimethylheptatriacontane & 20.04 \\
\hline
\end{tabular}


Table 2 Number of Aggressive Interactions Observed during the First 23 Days after Orphanage (552 Observation Hours). Aggressive Interactions only Occurred between Workers 1 and 2, during a Very Narrow Time Frame (6 to 8 Days after Orphaning)

\begin{tabular}{lccccc}
\hline Behaviour & 1 to 2 & 2 to 1 & Mutual & Total & Max. number of interactions per hour \\
\hline Antennal boxing & 24 & 7 & 4 & 35 & 3 \\
Biting & 4 & 2 & 0 & 6 & 10 \\
Lunging & 48 & 22 & 1 & 71 & 1 \\
Opposition & - & - & 6 & 6 & \\
Total & 76 & 31 & 11 & 118 &
\end{tabular}

\section{Sampling and Analysis of Cuticular Hydrocarbon Profiles Using SPME}

In order to sample ants using SPME, ants were individually removed from the nest box and fixed with a nylon string onto a wooden block. Subsequently, we rubbed a Supelco $7 \mu \mathrm{m}$ polydimethylsiloxane fibre against the ant's entire body for $3 \mathrm{~min}$. To avoid contamination, we avoided sampling the area around the paint marks. The sampled ant was then returned to the colony within 5 to $10 \mathrm{~min}$. The SPME fibre was inserted into a gas chromatograph [Agilent 6850 Series, Agilent Technologies, USA, equipped with a capillary column (Agilent HP-1; coated with methyl siloxane; length: 30 m; I.D.: $0.32 \mathrm{~mm}$; film thickness: $0.25 \mu \mathrm{m}$; Agilent Technologies, USA) and flame ionisation detector] and desorbed for $5 \mathrm{~min}$. Samples were analyzed in splitless mode. The injector and detector temperatures were $320^{\circ} \mathrm{C}$ and $300^{\circ} \mathrm{C}$ respectively, with an inlet pressure of $8.28 \mathrm{psi}$. The oven temperature was increased from $150^{\circ} \mathrm{C}$ to $200^{\circ} \mathrm{C}$ at $20^{\circ} \mathrm{C} / \mathrm{min}$, then to $290^{\circ} \mathrm{C}$ at $10^{\circ} \mathrm{C} / \mathrm{min}$, and held for $20 \mathrm{~min}$. We used helium as a carrier gas. Data were analyzed using ChemStation (Rev A.09.01, Agilent Technologies). After each run, a blank run was performed to clear any residual chemicals from the fibre.

\section{Behavioural Observation}

The following behaviours were considered signatures of aggression and scored accordingly: Antennal boxing, when an opponent was rapidly hit 3 to 5 times with the antennae. The high speed of antennal movement during antennal boxing clearly and easily distinguishes it from normal sensory antennal contact. Antennal boxing is likely to correspond with the rapid antennation described by Blatrix and Jaisson (2000). However, we prefer the more commonly used term 'antennal boxing'. Biting was scored when it could be clearly distinguished from grooming another ant's legs, which is when biting is preceded by a short, jerky movement. Lunging, when an ant quickly approached a nestmate, after which the nestmate moved away. Lunging most likely reflects in part an intention to bite the opponent. Opposition, when ants stood stationary

Fig. 1 Cuticular chemical profiles for Worker 5 at the time of first chemical sampling (a, representative profile for all workers) and for two workers at day 23 who either did (b, Worker 1) or did not activate (c, Worker 5) their ovaries. Only compounds correlated with reproductive status are labelled; numbers shown in white and black circles indicate peaks that are positively and negatively correlated with fertility, respectively (Lommelen et al. 2006). The peak numbers correspond to the identified compounds listed in Table 1. 


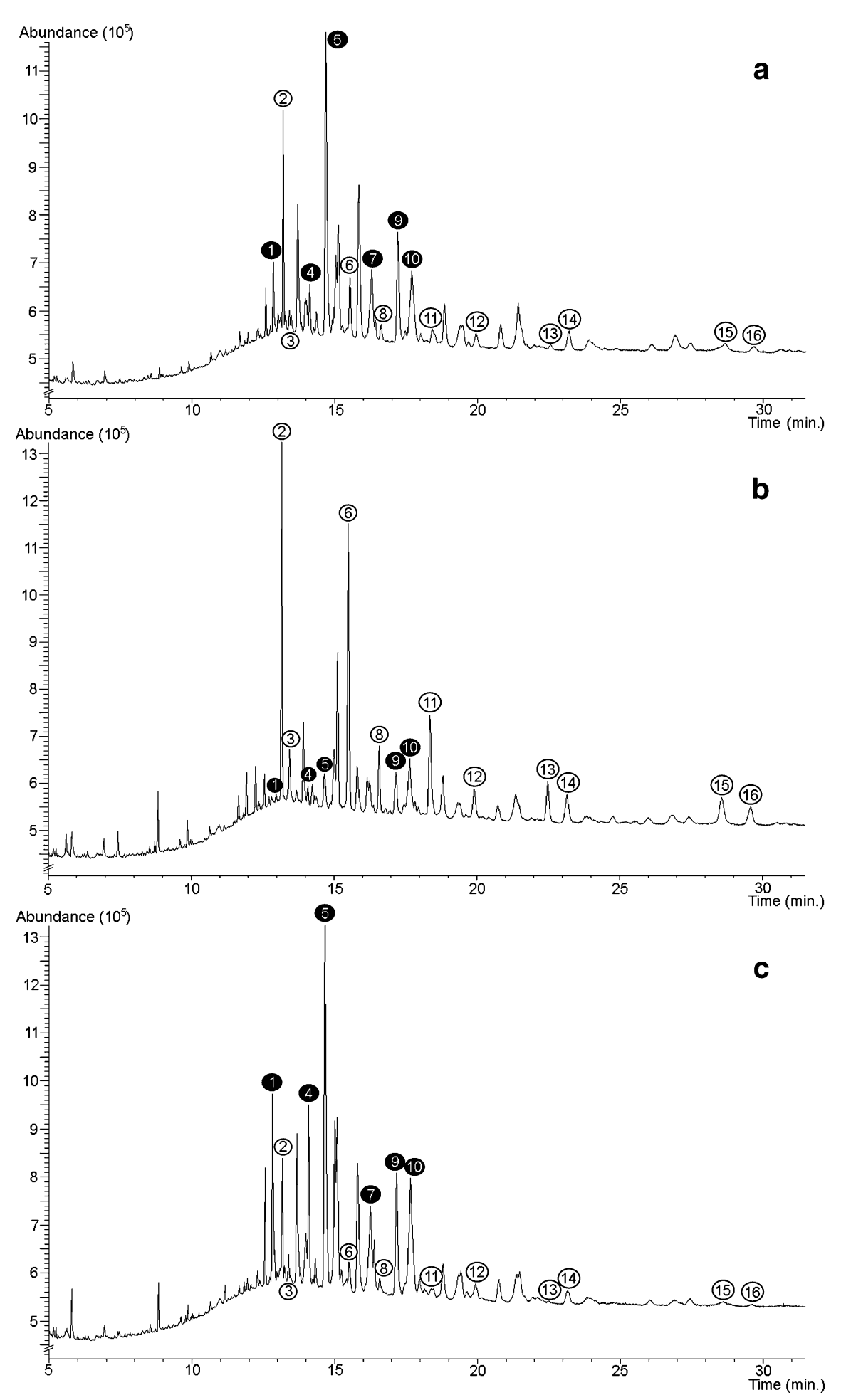


in front of each other for several minutes, with the antennae of the two ants spread in such a way that they crossed each other when viewed from above. This behaviour was often preceded or followed by antennal boxing or other dominance interactions.

We also scored other behaviours such as grooming, larval care and leaving the nest to forage.

\section{Results}

The forager positions were established early on, with the two 'manifested' foragers making trips outside the nest within the first 3 days. Aggressive interactions began on Day 6, and were restricted to just two individuals for only 34 of 552 observation hours (from Day 6 to Day 8). By Day 9, all aggression within the nest ended and three workers (Workers 1-3) developed their ovaries.

Overall, the frequency of aggressive interactions was relatively low even during the period of maximal conflict, which peaked at three antennal boxes and two bites per hour (Table 2). In between aggressive interactions, Workers 1 and 2 sometimes avoided each other, although there were frequent intervals of typical allogrooming.

The chemical profiles varied with the different behavioural tasks of the colony. Foragers had (1) relatively high concentrations of 9-, 11- and 13-MeC31, which coelute as peak 5, and other hydrocarbons (peaks 1, 4, 7, 9 and 10) that are negatively correlated with fertility (Lommelen et al. 2006), and (2) low concentrations of 3,11-, 3,13- and 3,15-diMeC31, which co-elute as peak 6, and other hydrocarbons (peaks 2, 3, 8 and 11 to 16) typically associated with high fertility (Table 1, Figs. 1 and 2). These chemical profiles that reflect low fertility, remained consistent throughout the experiment (Fig. 2). The chemical profiles of the reproducers, on the other hand, underwent unique changes during the experiment. At the start, the chemical profiles of the 2 weeks old workers were similar to those of the foragers. One week later, the chemicals of three workers (Workers 1-3) changed quickly and became similar to typical profiles of fertile individuals, with a marked decrease in the concentration of 9-, 11- and 13-MeC31 and an increase in the concentration of 3,11-, 3,13- and 3,15diMeC31 (Figs. 1 and 2, Table 1). Initially, the chemical profiles of Workers 1 and 2 were almost identical and changed simultaneously. However, the profiles began to diverge on Day 11, which is 2 days after Worker 1 had boxed and lunged at Worker 2 significantly more often (binomial test, $P=0.002$ and 0.001 , respectively, Table 2 ). Although not significant, Worker 1 tended to bite Worker 2 more frequently $(P=$ $0.34)$.

Dissection of all workers at the end of the experiment confirmed that the relative concentration of fertility-signalling chemicals, i.e. the ratio of 3,11-, 3,13- and 3,15diMeC31 to 9-, 11- and 13-MeC31, was correlated with the number of ovarioles, which is a strong indication of an individual's reproductive potential (Spearman, $R=0.95$, $P=0.01$ ). From the other quantified hydrocarbons, 8 out of 14 were significantly correlated with the number of ovarioles (peaks 7, 8, 10-14 and 16; Spearman, $R=$ $0.95, P=0.01)$. Of the ten foragers in the experimental colony, none had active ovaries.

A detailed day-by-day account of the behavioural and chemical characteristics of the individual ants is given below. Chemical samples of the six studied workers were 


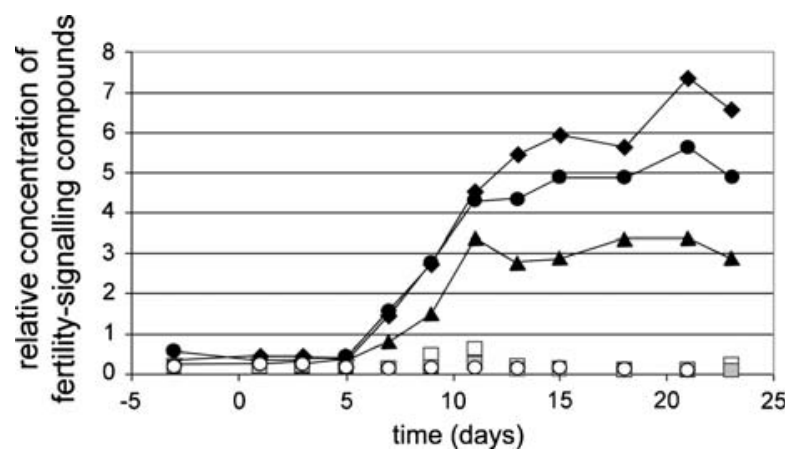

Fig. 2 Chemical changes in the six studied workers as a function of time after orphaning. Worker 6 is the control worker, which was left in the mother colony. The relative concentration of fertility-signalling chemicals is the concentration ratio of 3,11-, 3,13- and 3,15-diMeC31 (peak 6, Table 1) to 9-, 11- and 13MeC31 (peak 5, Table 1). Day 0 represents the day that five of the six workers were placed in a separate observation nest together with ten foragers. Dots (connected by lines) represent the six studied workers with numbering as referred to in the text $(\bullet$ Worker 1; • Worker 2; $\boldsymbol{\Delta}$ Worker 3; $\square$ Worker 4; ○ Worker 5; 口 Worker 6).

taken 3 days before the start of the experiment and on Days 1, 3, 5, 7, 9, 11, 13, 15 18, 21 and 23 (Fig. 2).

Day 0 A subset of workers was separated from the mother colony and settled into their nest.

Days 1-2 All workers except for Worker 5 in the experimental nest were inside standing still, grooming or caring for larvae. Worker 5 behaved like a forager and frequently made trips outside the nest. All workers had qualitatively similar cuticular hydrocarbon profiles, which were characterized by the presence of relatively high concentrations of 9-, 11- and 13-MeC31 and low concentrations of 3,11-, 3,13- and 3,15-diMeC31, (Table 1, Figs. 1 and 2), revealing their low fertility (Lommelen et al. 2006). The initial ratio of 3,11-, 3,13- and 3,15-diMeC31 to 9-, 11- and 13-MeC31, however, was slightly higher in Workers 1 to 3 than in Workers 4 and 5 (Table 3).

Table 3 Ovarian Development of the Five Studied Workers 23 Days after Orphaning, and of the 6th Control Worker, Which Remained in the Mother Colony. As Predicted, Ovarian Development was Significantly Correlated with the Final Relative Concentration of Fertility-signalling Chemicals, i.e. the Ratio of 3,11-, 3,13- and 3,15-diMeC31 (peak 6) to 9-, 11- and 13-MeC31 (peak 5) (Fig. 2)

\begin{tabular}{lccccc}
\hline $\begin{array}{l}\text { Worker } \\
\text { ovarioles }\end{array}$ & $\begin{array}{l}\text { Total number } \\
\text { of oocytes }\end{array}$ & $\begin{array}{l}\text { Number of oocytes } \\
\text { per ovariole }\end{array}$ & $\begin{array}{l}\text { Initial ratio of peak } \\
\text { 6 to peak 5 (day 1) }\end{array}$ & $\begin{array}{l}\text { Final ratio of peak } \\
\text { 6 to peak 5 }\end{array}$ \\
\hline 1 & 4 & 6 & 1.5 & 0.26 & 6.53 \\
2 & 4 & 4 & 1 & 0.33 & 4.86 \\
3 & 3 & 6 & 2 & 0.45 & 2.89 \\
4 & 2 & 1 & 0.5 & 0.14 & 0.23 \\
5 & 2 & 0 & 0 & 0.22 & 0.08 \\
6 & 3 & 0 & 0 & 0.17 & 0.08 \\
\hline
\end{tabular}


Days 3-5 A second worker (Worker 4) began making trips outside the nest and foraging. The cuticular hydrocarbons of all workers on Days 3 and 5 were still the same as on Day 1.

Day 6 Aggressive interactions were observed between Workers 1 and 2. Workers 1, 2 and 3 spent all of their time within the nest.

Day 7 The chemical sampling on this day showed that there was a notable change in the chemical profiles of Workers 1, 2 and 3. The concentration of 3,11-, 3,13- and 3,15-diMeC31 exceeded that of 9-, 11- and 13-MeC31 in workers 1 and 2, and was almost equal in worker 3 (Fig. 2). Workers 1 and 2 had identical chemical profiles.

Day 8 Workers 1 and 2 interacted aggressively again during the night.

Day 9 All aggressive interactions ceased completely. The concentration of 3,11-, 3,13- and 3,15-diMeC31 continued to increase in Workers 1, 2 and 3, almost doubling in two days, while the concentration of 9-, 11- and 13-MeC31 dropped by $50 \%$ (Fig. 2). All these changes are typically associated with an increase in fertility or ovarian development.

Day 11 The chemical profiles of Workers 1 and 2, which had remained similar until Day 9 , began to diverge, with the concentration of fertility signalling hydrocarbons (3,11-, 3,13- and 3,15-diMeC31) increasing more quickly in Worker 1, who had behaved most aggressive on Days 6 and 8 .

Days 12-23 During the last part of the experiment, no aggression was observed, and chemicals of Workers 1, 2 and 3 slowly morphed towards a chemical profile revealing higher fertility (Fig. 2). In comparison, gamergates signal a much higher fertility, with a ratio of 3,11-, 3,13- and 3,15-diMeC31 to 9-, 11- and 13-MeC31 above 10, while Worker 1 reached a ratio of 7 . This indicates that the dominants had not yet reached the level of fecundity of gamergates, which was confirmed by dissection that showed fewer developing oocytes than expected from a gamergate.

\section{Discussion}

Our results show that subtle differences in cuticular chemistry associated with reproductive potential are critical in the initial division of labour during the early stages of establishing a reproductive hierarchy in orphaned gamergate colonies of Gnamptogenys striatula (Fig. 3, steps 1-2). The two workers that became foragers (Workers 4 and 5) had indeed the lowest potential fertility (i.e., 2 vs. 3-4 ovarioles, Table 3) and cuticular profiles that are associated with low fertility. Only later and for a short period (3 days) was intra-nest aggression important to establish further ranking between the two ants with the highest potential fertility and the same highfertility chemical signals (Workers 1 and 2 with four ovarioles, Table 3 and Fig. 2; Fig. 3, step 3). This aggression ceased once the chemical profile of the most 


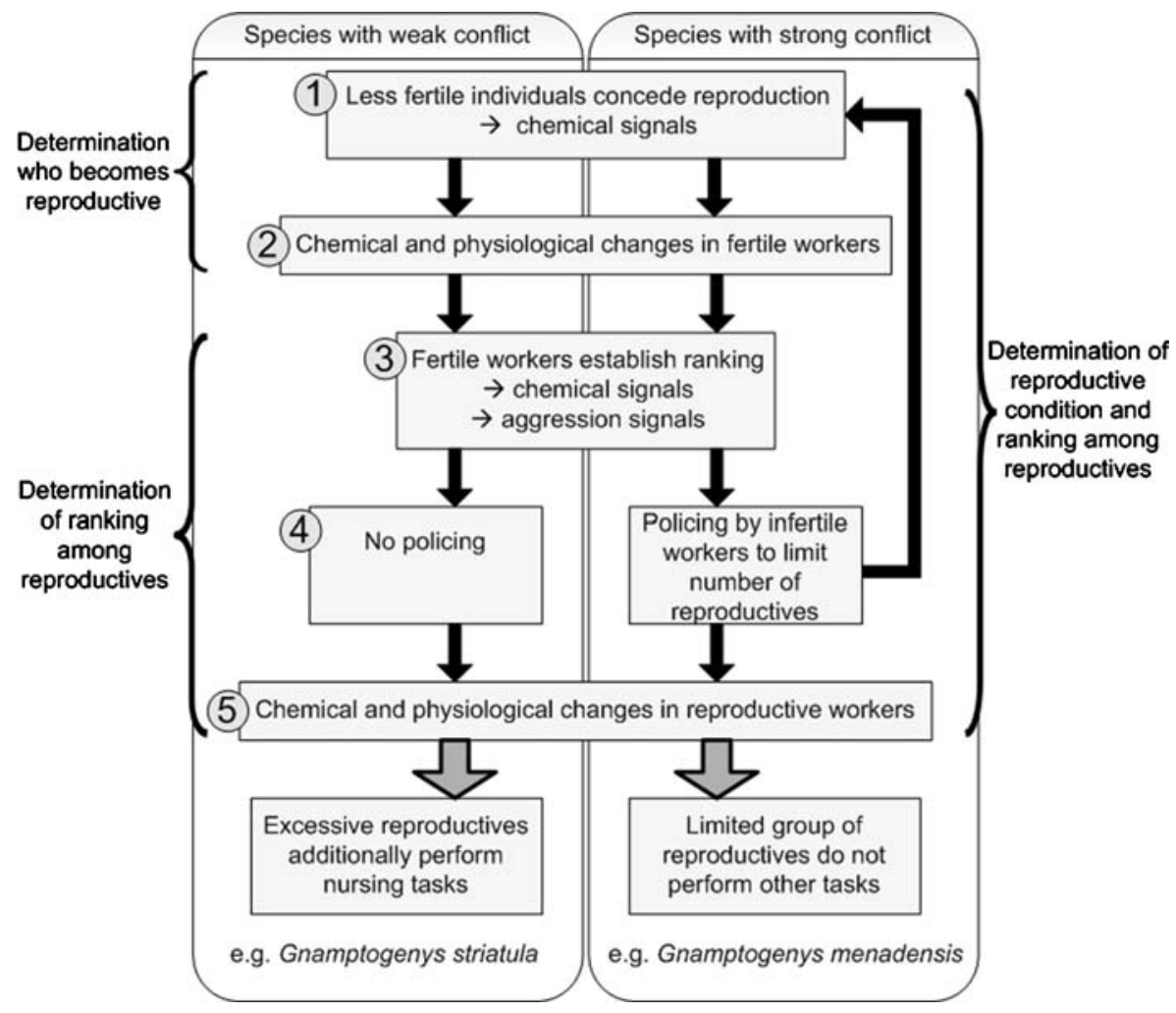

Fig. 3 Schedule summarizing the different steps and phases during establishment of a new dominance hierarchy, and the signals ants are using during these steps (see also text). Black arrows indicate the chronological order of the steps and grey arrows the result.

aggressive worker indicated higher fertility. After aggression diminished, the cuticular hydrocarbon pattern of the three dominant ants continued to morph towards a pattern that reflected their respective fertility (Fig. 3, step 5). These changes in cuticular chemicals most likely reflect hormonal and physiological changes (Cuvillier-Hot et al. 2004a).

Probably the most remarkable result of our experiment was that the final concentration of chemical fertility signals correlated very strongly with the ants' ovariole numbers, which in this species have been shown to vary as a consequence of differences in the feeding regimes of larvae (Kaptein et al. 2005). Given that all ants in our experiment had the same age and were treated in the same way, ovariole numbers were likely the only initial difference in fertility and they are moreover a good indicator of each ant's potential intrinsic fertility. Within a week, this initial difference in fertility was indicated in the ants' cuticular chemicals, on which ants may rely to judge each other's fertility and to possibly concede reproduction.

Based on inclusive fitness theory (Hamilton 1964), one can see that a strategy of conceding reproduction to more fertile nestmates would be evolutionarily stable when $p_{L F}<p_{H F} . r$ where $p_{L F}$ and $p_{H F}$ are the hypothetical productivities when the 
colony would be headed by a low-fertility or a high-fertility individual, respectively, and $r$ is the relatedness between them. In this equation, the left-hand side is the direct benefit of reproducing oneself, and the right-hand side is the indirect benefit of allowing the other highly fertile individual to reproduce. In $G$. striatula, the relatedness $r$ between gamergates has been found to be close to 0.75 , since queens are generally single-mated (Giraud et al. 2000; Savarit et al. 2001), and orphaning would be more likely when queen number had already reduced to a low number (gamergates are only produced in the absence of a queen, Blatrix and Jaisson 2000). Assuming that ovariole number is in this experiment a good indicator of an individual's initial and potential fertility, we can see that workers with two ovarioles should concede reproduction to workers with at least three ovarioles. This prediction indeed corresponds to our findings (Table 3). In natural colonies, ovariole numbers range from 2 to 8 (Blatrix and Jaisson 2001) and gamergates have on average higher ovariole numbers than workers (Blatrix and Jaisson 2000). This confirms our experimental result that individuals with a higher ovariole number have a better chance of becoming a new reproductive.

Because oocyte number can be considered an indicator of actual fertility and is reflected in the cuticular chemical profile (Lommelen et al. 2006), the cuticular chemicals provide a reliable, honest signal of true fertility, which other ants appear to respect. Honest signalling theory predicts that cheap signals such as pheromones can be evolutionarily stable (1) if the relatedness between signaller and receiver is high (Reeve 1997), or (2) producing dishonest signals carries significant direct or inclusive fitness costs for the signaller (Lachmann et al. 2001). As discussed before, within nest relatedness before orphaning is high in G. striatula. On the other hand, policing imposes an additional cost which could discourage workers from cheating (E. Lommelen, pers. obs.).

The apparently peaceful way in which $G$. striatula regulates reproduction forms an interesting contrast to what is seen in the congeneric species Gnamptogenys menadensis (Mayr). Here, the establishment of a new dominance hierarchy takes longer and involves a long period of aggression. In G. menadensis antennal boxing was common for up to 5 weeks after colony orphaning (in contrast to 3 days in $G$. striatula) and the frequencies (five bouts per worker per hour, Gobin et al. 2001) were much greater than in the present study on G. striatula ( 0.03 bouts per worker per hour). As a result of this aggression, 20 orphaned G. menadensis workers require an average of 93 days (S.D. $=30 ; n=6$ ) to produce a pile of five eggs whereas $G$. striatula workers require only an average of 24 days (S.D. $=10 ; n=12$; E. Lommelen and C. Johnson, pers. obs.). These comparisons, however, should be treated somewhat cautiously, given that the data on aggression from the present study were based on observations on just a single colony.

These differences are likely caused by the different ways in which both species deal with excess reproductives. After orphaning, G. striatula produces an excess of individuals that develop their ovaries and attempt to mate and become gamergates. Nevertheless, because gamergates do colony work (Blatrix and Jaisson 2000), an overproduction of gamergates incurs no cost to the colony. By contrast, $G$. menadensis gamergates function only as reproductives, and so each additional gamergate imposes an additional cost to the colony. Therefore, there is strong selection to limit the number of reproductives in G. menadensis by aggressively 
immobilizing lower ranked individuals that attempt to challenge the top-ranker, which results in those individuals losing their dominant position (Fig. 3, steps 3-4-1; Gobin et al. 2001). Such culling of low ranked reproductives in the group that initially attempted to become a reproductive via aggressive policing is the evident cause of prominent dominance interactions and a lengthened period during which a dominance hierarchy is established (Fig. 3).

The differential costs of additional gamergates to G. striatula and G. menadensis colonies determine the need for culling of reproductives during establishment of a dominance hierarchy and consequently also the presence and strength of aggression. Thus a large number of individuals that initially attempt to become a reproductive relative to the number of individuals that is entitled to become a reproductive causes widespread aggression. The same argument probably explains the aggression seen after orphanage in the queenless ants Dinoponera quadriceps (Monnin and Peeters 1998), Pachycondyla (Bothroponera) sp. (Ito 1993b), P. sublaevis (Ito and Higashi 1991) and Streblognathus peetersi (Cuvillier-Hot et al. 2004a), where only one individual becomes the new gamergate although several dominant workers apply for the job. In Harpegnathos saltator, it could well be that the constant number of eight ovarioles (Peeters et al. 2000) limits the initial variation in fertility such that most individuals are equally suitable to become a reproductive. We could, therefore, expect aggression to reduce this excess of candidate-reproductives. In Pachycondyla berthoudi (Peeters and Crewe 1984) and Rhytidoponera sp. 12 (Peeters 1987), on the other hand, insemination is the prime determinant of reproductive number. Among the inseminated ants, there is no further reduction in the number of reproductives, nor is there any selection of who is allowed to mate (Peeters and Crewe 1984; Peeters 1987). In P. berthoudi, young gamergates engage in nonreproductive labour to counterbalance an overflow of gamergates (Sledge et al. 1999), similar to G. striatula. As hypothesized above for G. striatula, the lack of culling reproductives during establishment of a new dominance hierarchy makes strong aggression redundant. There is indeed evidence that dominance interactions are absent in P. berthoudi and R. sp. 12 (Peeters and Crewe 1984; Sledge et al. 2001; Tay and Crozier 2000).

In conclusion, our study shows five relatively distinct steps during establishment of a dominance hierarchy (Fig. 3). Soon after orphaning, less fertile individuals concede reproduction to their more fertile nestmates by relying on small initial differences in fertility (i.e. higher ovariole number) that are signalled through cuticular hydrocarbon profiles. Secondly, the absence of any reproductives is likely to lead to physiological and hormonal changes in fertility in more fertile individuals, which is reflected in a change in cuticular hydrocarbons 1 week later. Similarities in these changing chemicals inevitably lead to aggression in a third phase, where a ranking is established among reproductives. As infertile workers can rely on other ants' chemicals and aggressive behaviour at this step, they can start policing an overflow of dominant workers if necessary. Culling of dominant workers seems to influence the strength of aggression between them. Finally, after aggression has determined a new hierarchy, high-ranking workers will develop their ovaries further and simultaneously alter their hydrocarbon pattern towards that of a reproductive. 
Acknowledgements We would like to thank A. Vandoren for technical assistance and Prof. F. Ollevier for valuable suggestions. MINAE granted permission to collect the ants in Costa Rica (resolucion nr. 1312002-OFAU and 282-2003-OFAU). We also thank the Research Council of the University of Leuven (research project 01.24), the Fund for Scientific Research-Flanders (Belgium, research project G.0247.02). TW was supported by a grant from the Flemish Fund for Scientific Research—Flanders.

\section{References}

Blatrix R, Jaisson P (2000) Optional gamergates in the queenright ponerine ant Gnamptogenys striatula Mayr. Insect Soc 47:1-5

Blatrix R, Jaisson P (2001) Reproductive strategy of the ponerine ant Gnamptogenys striatula Mayr (Hymenoptera: Formicidae). Sociobiology 37:147-161

Bourke AFG (2005) Genetics, relatedness and social behaviour in insect societies. In: Fellowes MDE, Holloway GJ, Rolff J (eds) Insect evolutionary ecology. CABI, Wallingford, pp 1-30

Bourke AFG, Franks NR (1995) Social evolution in ants. Princeton University Press, Princeton

Cole BJ (1986) The social behavior of Leptothorax allardycei (Hymenoptera, Formicidae): time budgets and the evolution of worker reproduction. Behav Ecol Sociobiol 18:165-173

Cuvillier-Hot V, Gadagkar R, Peeters C, Cobb M (2002) Regulation of reproduction in a queenless ant: aggression, pheromones and reduction in conflict. Proc R Soc Lond B Biol Sci 269:1295-1300

Cuvillier-Hot V, Lenoir A, Crewe R, Malosse C, Peeters C (2004a) Fertility signalling and reproductive skew in queenless ants. Anim Behav 68:1209-1219

Cuvillier-Hot V, Lenoir A, Peeters C (2004b) Reproductive monopoly enforced by sterile police workers in a queenless ant. Behav Ecol 15:970-975

D'Ettorre P, Heinze J, Schulz C, Francke W, Ayasse M (2004) Does she smell like a queen? Chemoreception of a cuticular hydrocarbon signal in the ant Pachycondyla inversa. J Exp Biol 207:1085-1091

Dietemann V, Liebig J, Hölldobler B, Peeters C (2005) Changes in the cuticular hydrocarbons of incipient reproductives correlate with triggering of worker policing in the bulldog ant Myrmecia gulosa. Behav Ecol Sociobiol 58:486-496

Giraud T, Blatrix R, Poteaux C, Solignac M, Jaisson P (2000) Population structure and mating biology of the polygynous ponerine ant Gnamptogenys striatula in Brazil. Mol Ecol 9:1835-1841

Gobin B, Billen J, Peeters C (1999) Policing behaviour towards virgin egg layers in a polygynous ponerine ant. Anim Behav 58:1117-1122

Gobin B, Billen J, Peeters C (2001) Dominance interactions regulate worker mating in the polygynous ponerine ant Gnamptogenys menadensis. Ethology 107:495-508

Gobin B, Heinze J, Strätz M, Roces F (2003) The energetic cost of reproductive conflicts in the ant Pachycondyla obscuricornis. J Insect Physiol 49:747-752

Hamilton WD (1964) The genetical evolution of social behaviour. I \& II. J Theor Biol 7:1-52

Hart AG, Ratnieks FLW (2005) Crossing the taxonomic divide: conflict and its resolution in societies of reproductively totipotent individuals. J Evol Biol 18:383-395

Hartmann A, Wantia J, Torres JA, Heinze J (2003) Worker policing without genetic conflicts in a clonal ant. Proc Natl Acad Sci USA 100:12836-12840

Hartmann A, D' Ettorre P, Jones GR, Heinze J (2005) Fertility signaling-the proximate mechanism of worker policing in a clonal ant. Naturwissenschaften 92:282-286

Hölldobler B, Wilson EO (1990) The ants. Springer-Verlag, Berlin

Ito $\mathrm{F}$ (1993a) Social organisation in a primitive ponerine ant-queenless reproduction, dominance hierarchy and functional polygyny in Amblyopone sp. (reclinata group) (Hymenoptera: Formicidae: Ponerinae). J Nat Hist 27:1315-1324

Ito F (1993b) Functional monogyny and dominance hierarchy in the queenless ponerine ant Pachycondyla (= Bothroponera $)$ sp. in West Java, Indonesia (Hymenoptera, Formicidae, Ponerinae). Ethology 95:126-140

Ito F, Higashi S (1991) A linear dominance hierarchy regulating reproduction and polyethism of the queenless ant Pachycondyla sublaevis. Naturwissenschaften 78:80-82

Iwanishi S, Hasegawa E, Ohkawara K (2003) Worker oviposition and policing behaviour in the myrmicine ant Aphaenogaster smynthiesi japonica Forel. Anim Behav 66:513-519

Kaptein N, Billen J, Gobin B (2005) Larval begging for food enhances reproductive options in the ponerine ant Gnamptogenys striatula. Anim Behav 69:293-299 
Kawabata S, Tsuji K (2005) The policing behavior 'immobilization' towards ovary-developed workers in the ant, Diacamma sp. from Japan. Insect Soc 52:89-95

Kikuta N, Tsuji K (1999) Queen and worker policing in the monogynous and monandrous ant, Diacamma sp. Behav Ecol Sociobiol 46:180-189

Lachmann M, Számado S, Bergstrom CT (2001) Cost and conflict in animal signals and human language. Proc Natl Acad Sci USA 98:13189-13194

Liebig J, Hölldobler B, Peeters C (1998) Are ant workers capable of colony foundation? Naturwissenschaften 85:133-135

Liebig J, Peeters C, Hölldobler B (1999) Worker policing limits the number of reproductives in a ponerine ant. Proc R Soc Lond B Biol Sci 266:1865-1870

Lommelen E, Johnson CA, Drijfhout FP, Billen J, Wenseleers T, Gobin B (2006) Cuticular hydrocarbons provide reliable cues of fertility in the ant Gnamptogenys striatula. J Chem Ecol 32:2023-2034

Molet M, Van Baalen M, Monnin T (2005) Dominance hierarchies reduce the number of hopeful reproductives in polygynous queenless ants. Insect Soc 52:247-256

Monnin T (2006) Chemical recognition of reproductive status in social insects. Ann Zool Fenn 43:515-530

Monnin T, Peeters C (1998) Monogyny and regulation of worker mating in the queenless ant Dinoponera quadriceps. Anim Behav 55:299-306

Monnin T, Peeters C (1999) Dominance hierarchy and reproductive conflicts among subordinates in a monogynous queenless ant. Behav Ecol 10:323-332

Monnin T, Ratnieks FLW (1999) Reproduction versus work in queenless ants: when to join a hierarchy of hopeful reproductives? Behav Ecol Sociobiol 46:413-422

Monnin T, Ratnieks FLW (2001) Policing in queenless ponerine ants. Behav Ecol Sociobiol 50:97-108

Monnin T, Ratnieks FLW, Jones GR, Beard R (2002) Pretender punishment induced by chemical signalling in a queenless ant. Nature 419:61-65

Oliveira PS, Hölldobler B (1991) Agonistic interactions and reproductive dominance in Pachycondyla obscuricornis (Hymenoptera: Formicidae). Psyche 98:215-225

Peeters CP (1987) The reproductive division of labour in the queenless ponerine ant Rhytidoponera sp. 12. Insect Soc 34:75-86

Peeters C, Crewe R (1984) Insemination controls the reproductive division of labour in a ponerine ant. Naturwissenschaften 71:50-51

Peeters C, Liebig J, Hölldobler B (2000) Sexual reproduction by both queens and workers in the ponerine ant Harpegnathos saltator. Insect Soc 47:325-332

Powell S, Tschinkel WR (1999) Ritualized conflict in Odontomachus brunneus and the generation of interaction-based task allocation: a new organizational mechanism in ants. Anim Behav 58:965-972

Ratnieks FLW, Foster KR, Wenseleers T (2006) Conflict resolution in insect societies. Annu Rev Entomol 51:581-608

Reeve HK (1997) Evolutionarily stable communication between kin: a general model. Proc R Soc Lond B Biol Sci 264:1037-1040

Reeve HK, Keller L (2001) Tests of reproductive-skew models in social insects. Annu Rev Entomol 46:347-385

Savarit F, Poteaux C, Blatrix R, Jaisson P (2001) Colony structure and reproductive strategies in Gnamptogenys striatula. P 144 Proceedings of the 2001 Berlin meeting of the European sections of IUSSI, Sept. 25-29

Sledge MF, Peeters C, Crewe RM (1999) Fecundity and the behavioural profile of reproductive workers in the queenless ant, Pachycondyla ( = Ophthalmopone) berthoudi. Ethology 105:303-316

Sledge MF, Peeters C, Crewe RM (2001) Reproductive division of labour without dominance interactions in the queenless ponerine ant Pachycondyla (= Ophthalmopone) berthoudi. Insect Soc 48:67-73

Strassmann JE, Sullender BW, Queller DC (2002) Caste totipotency and conflict in a large-colony social insect. Proc R Soc Lond B Biol Sci 269:263-270

Tay WT, Crozier RH (2000) Nestmate interactions and egg-laying behaviour in the queenless ponerine ant Rhytidoponera sp. 12. Insect Soc 47:133-140

Trunzer B, Heinze J, Hölldobler B (1999) Social status and reproductive success in queenless ant colonies. Behaviour 136:1093-1105

Ward PS (1981) Ecology and life history of the Rhytidoponera impressa group (Hymenoptera: Formicidae). II. Colony origin, seasonal cycles, and reproduction. Psyche 88:109-126

Ware AB, Compton SG, Robertson HG (1990) Gamergate reproduction in the ant Streblognathus aethiopicus Smith (Hymenoptera: Formicidae: Ponerinae). Insect Soc 37:189-199

Wildman MH, Crewe RM (1988) Gamergate number and control over reproduction in Pachycondyla krugeri (Hymenoptera: Formicidae). Insect Soc 35:217-225

Wilson EO (1971) The insect societies. Harvard University Press, Cambridge 